\title{
Paul Gold To Continue as Psychobiology Editor
}

The Publications Committee of the Psychonomic Society is pleased to announce that Paul Gold, the current editor of Psychobiology, has agreed to extend his term by at least 1 year (through 1995). This will give him more time to implement some of the changes in the journal that grew out of the recent review and analysis of Psychobiology. That review affirmed the importance of the journal to the Society (and to the field in general) and endorsed a variety of changes suggested by members of the Society and by Dr. Gold.

\author{
23rd Annual Meeting of the Society for Computers in Psychology \\ Washington, D.C. \\ November 4, 1993
}

\section{Call for Papers}

The 23rd Annual Meeting of the Society for Computers in Psychology will be held at the Shoreham Hotel in Washington, DC, on November 4, 1993, the day before the annual meeting of the Psychonomic Society. The meeting will include presentations, workshops, tutorials, and demonstrations. The application of computerbased solutions to all areas of psychology will be featured, including research, education, clinical practice, and industrial applications. The proceedings will be published in Behavior Research Methods, Instruments, \& Computers.

The deadline for submissions is June 25, 1993.

For further information, contact Nancy Duncan, Department of Psychology, Hampton University, Hampton, VA $23668<71043,1340 @$ compuserv.com > or Ellen Rosen, Department of Psychology, College of William and Mary, Williamsburg, VA 23187 <Internet:EFROSE.MAIL.WM.EDU >. 